\title{
Association of Ultrasound Estimated Fetal Weight between 10th and 50th Centile in Third Trimester with the Risk of Spontaneous Preterm Delivery
}

\author{
${ }^{1}$ Muralidhar V Pai, ${ }^{2}$ Caroline R Mathias
}

\begin{abstract}
Objective: To find out the association of ultrasound estimated fetal weight (UEFW) between 10th and 50th centile, in early third trimester and the risk of spontaneous preterm delivery.

Materials and methods: Fetal weight of 965 women with singleton pregnancy was estimated between 28 and 34 weeks. Women with multiple gestation, medical disorders, fetal anomalies and induced labor were excluded. Values of UEFW were converted into centile values and multiples of median (MoM) for each gestational age. The risk of spontaneous preterm delivery was correlated with the UEFW.
\end{abstract}

Results: Out of 965 subjects 62 were either excluded as per exclusion criteria or lost for follow-up. Out of 91 subjects with fetal weights $\leq 10$ th centile $17(18.7 \%$, OR 1.82 , p-value 0.003$)$ and out of 180 with that $\leq 20$ th centile $29(16.1 \%$ OR 1.51 , $\mathrm{p}$-value 0.040$)$ had preterm delivery. When the deviation was below 0.85 MoM, 15 out of 73 (20.5\% OR 2.08, p-value 0.024$)$ subjects had preterm delivery.

Conclusion: When UEFW in early third trimester is below 20th centile or below $0.80 \mathrm{MoM}$ the risk for spontaneous preterm delivery increases, hence, it may be prudent to be vigilant when the fetal weight is between 10th and 20th centile to avoid preterm delivery.

Keywords: Fetal growth restriction, Preterm delivery, Ultrasound estimated fetal weight.

How to cite this article: Pai MV, Mathias CR. Association of Ultrasound Estimated Fetal Weight between 10th and 50th Centile in Third Trimester with the Risk of Spontaneous Preterm Delivery. Int J Infertil Fetal Med 2015;6(3):108-111.

Source of support: Nil

Conflict of interest: None

Date of received: $10-09-15$

Date of acceptance: $12-11-15$

Date of publication: December 2015

\footnotetext{
${ }^{1}$ Professor, ${ }^{2}$ Resident

1,2Department of Obstetrics and Gynecology, Kasturba Medical College, Manipal, Karnataka, India
}

Corresponding Author: Muralidhar V Pai, Department of Obstetrics and Gynecology, Kasturba Medical College, Manipal Karnataka, India, Phone: 00918202922379, e-mail: drmvpai@ yahoo.com

\section{INTRODUCTION}

Preterm delivery is a result of variety of mechanisms activating the common pathway of parturition. Intrauterine infection, uterine ischemia, immune reaction and endocrine disorders are pointed as potential causal factors, and the same may indirectly trigger pathological and adaptive mechanisms affecting fetal growth. The fetus is considered to be growth restricted when its weight is less than 10th centile of its peers in a given gestational age and pregnancies with growth restricted fetuses are known to be vulnerable for preterm labor (PTL). Filiberto M Severi and co-workers concluded that ultrasound estimated fetal weight (UEFW) slightly below the median also is associated with increased risk of spontaneous preterm birth. ${ }^{1}$ This study was conducted to find out the association of UEFW between 10th and 50th centile, as well as weight below the median in early third trimester (28-34 weeks) and the risk of spontaneous preterm delivery.

\section{MATERIALS AND METHODS}

It was a prospective, case-control study conducted at the Department of Obstetrics and Gynecology, Kasturba Medical College, Manipal, Manipal University, India, between September 2012 and August 2014. The study was approved by the institutional ethics committee and informed consent was obtained from each participant.

Fetal weight of 965 women with singleton pregnancy was estimated using $5 \mathrm{MHz}$ transabdominal transducer of Toshiba Nimio ultrasound machine, between 28 and 34 weeks. Women with multiple gestation, medical disorders, fetal anomalies and induced labor were excluded. Maternal age, parity, medical and obstetric history were noted. General physical, systemic and obstetric examination were performed. Gestational age was defined according to the last menstrual period.

'Sonocare' software developed by Medialogic Solutions, Chennai, India, was used to calculate the fetal weight. The centile values for each gestation were calculated after ensuring that each period of gestation had a minimum of 100 subjects and they were as given in Table 1. 
Table 1: Centile values for each gestation

\begin{tabular}{llllll}
\hline $\begin{array}{l}\text { POG in } \\
\text { completed weeks }\end{array}$ & EFW at 10th centile & EFW at 20th centile & EFW at 30th centile & EFW at 40th centile & EFW at 50th centile \\
\hline 28 weeks & 985.20 & 1011.0 & 1053.90 & 1076.00 & 1112.00 \\
29 weeks & 1100.00 & 1146.80 & 1190.60 & 1222.00 & 1255.00 \\
30 weeks & 1179.40 & 1256.80 & 1327.40 & 1387.0 & 1435.00 \\
31 weeks & 1320.00 & 1433.20 & 1473.80 & 1551.20 & 1571.00 \\
32 weeks & 1550.60 & 1601.00 & 1655.30 & 1689.80 & 1748.50 \\
33 weeks & 1695.00 & 1765.60 & 1864.80 & 1932.00 & 1989.00 \\
34 weeks & 1859.00 & 1965.0 & 2013.80 & 2099.40 & 2157.00 \\
\hline
\end{tabular}

Values of UEFW were converted first into centile values and then into multiples of median (MoM) for each gestational age. The risk of spontaneous preterm delivery was correlated with the UEFW.

Quantitative variables were summarized as means \pm standard deviation and differences between the two groups were assessed by unpaired student's t-test. For dichotomous variables, Pearson Chi-square test was used and statistical significance was assumed whenever $\mathrm{p}<0.05$. The odds ratio for preterm parturition syndrome were calculated for several cut-off points of UEFW expressed in both centiles and MoMs.

\section{RESULTS}

Out of 965 subjects recruited for the study, 62 were either excluded as per exclusion criteria or lost for followup hence only 903 were considered for final analysis (Flow Chart 1).

Out of 903 subjects, 91 (10.1\%) had fetuses with $\mathrm{UEFW} \leq 10$ centile for their period of gestation; $89(9.9 \%)$ had them between 11th and 20th centile, $88(9.7 \%)$ had between 21st and 30th centile, 94 (10.4\%) had between 31 st and 40th centile, $87(9.6 \%)$ had between 41 st and 50 th centile and $454(50.3 \%)$ had fetuses weighing above 50th centile (Table 2). A total age, parity and the mean gestational age at which the UEFW was performed in subjects delivered at term and preterm were matched. The mean UEFW at the time of estimation of fetuses that delivered at preterm was $1455.57 \pm 329.54 \mathrm{gm}$ and that of fetuses delivered at term was $1642.80 \pm 378.94 \mathrm{gm}$. This

Flow Chart 1: Consort statement

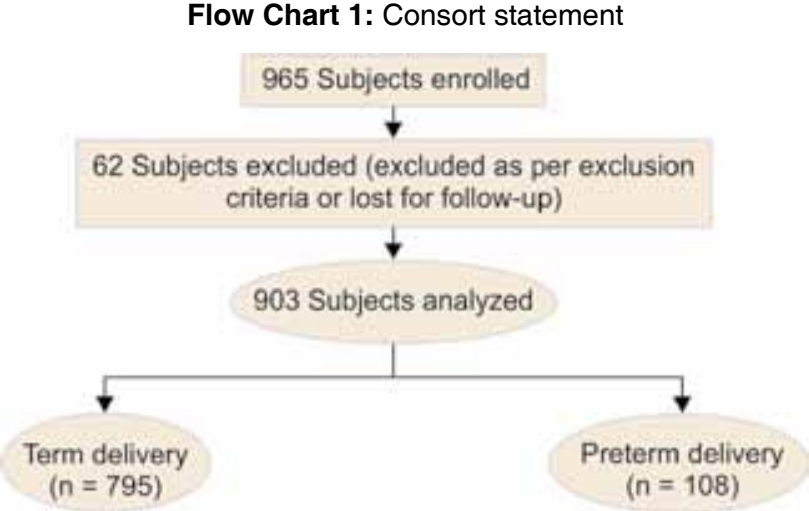

Table 2: Distribution of subjects in different centile ranges $\mathrm{n}=903$

\begin{tabular}{ll}
\hline Centile range & Number of women $(\%)$ \\
\hline S10th & $91(10.1 \%)$ \\
11th-20th & $84(9.9 \%)$ \\
21st-30th & $88(9.7 \%)$ \\
31st-40th & $94(10.4 \%)$ \\
41st-50th & $87(9.6 \%)$ \\
>50th & $454(50.3 \%)$ \\
\hline
\end{tabular}

difference was statistically significant $(\mathrm{p}=0.028)$. The mean gestational age of fetuses that had preterm delivery was $34.22 \pm 1.98$ weeks and their mean birth weight was $2187.50 \pm 499.74 \mathrm{gm}$ whereas those were $38.38 \pm$ 1.09 weeks and $2187.50 \pm 499.74$ gm respectively. These differences were statistically highly significant $(\mathrm{p}=0.000$ and 0.000) (Table 3).

Table 4 shows the risk of preterm delivery when the UEFWs were equal to or less than 10th, 20th, 30th, 40th and 50th centiles. Out of 91 women whose fetal weights were $\leq 10$ th centile 17 (18.7\%, OR 1.82) women had preterm delivery. Out of 180 that had fetuses weighing $\leq 20$ th centile $29(16.1 \%$ OR 1.51$)$ delivered preterm. These two findings were statistically significant ( $\mathrm{p}$-values: 0.033 and 0.040 respectively).

When the fetal weights were $\leq 30$ th centile 38 out of 268 (14.2\% OR 1.33), when that were $\leq 40$ th centile 48 out of $362(13.3 \%$ OR 1.24$)$ and when that were $\leq 50$ th centile 59 out of 454 (13.1\% OR 1.20) women had preterm delivery. These findings were statistically not significant ( $\mathrm{p}$-values: $0.112,0.189$ and 0.162 respectively).

Table 5 shows the risk of preterm delivery when the UEFWs were below 0.90, 0.85, 0.80, 0.75 MoM. Out of 169 women whose fetal weights had deviation below $0.90 \mathrm{MoM}$, 25 (14.8\%, OR 1.36) women had preterm delivery. This finding was statistically not significant (p-value: 0.131 ).

When the deviation was below $0.85 \mathrm{MoM}, 15$ out of 73 (20.5\% OR 2.08) women, when the deviation was below $0.80 \mathrm{MoM}, 9$ out of 31 ( $29 \%$ OR 3.19) women and when the deviation was below $0.75 \mathrm{MoM} 6$ out of 12 (50\% OR 7.77) had preterm delivery. These findings had statistical significance (p-values: 0.024, 0.007 and 0.001 respectively). 
Table 3: Demographic and clinical parameters of subjects delivered at preterm and term $(n=903)$

\begin{tabular}{llll}
\hline Characteristics & Preterm delivery $(n=108)$ & Term delivery $(n=795)$ & $p$-value \\
\hline Maternal age (years) & $27.67 \pm 4.53$ & $28.20 \pm 4.07$ & 0.143 \\
Primigravida & 70 & 503 & 0.515 \\
Multigravida & 38 & 292 & 0.056 \\
Mean gestational age at ultrasound & $30.33 \pm 1.68$ & $31.17 \pm 1.89$ & \\
estimation (in completed weeks) & & $1642.80 \pm 378.94$ & 0.028 \\
Mean UEFW at estimation (in grams) & $1455.57 \pm 329.54$ & $38.38 \pm 1.09$ & 0.000 \\
Mean gestational age at delivery & $34.22 \pm 1.98$ & $2994.04 \pm 383.26$ & 0.000 \\
Mean weight at delivery & $2187.50 \pm 499.74$ & & \\
\hline
\end{tabular}

Statistical test-independent samples t-test; $p$-value significant if $<0.05$

Table 4: Correlation between the risk of preterm delivery with UEFWs equal to or less than 10th, 20th, 30th, 40th and 50th centiles $(n=903)$

\begin{tabular}{|c|c|c|c|c|}
\hline Centile values & Preterm delivery $(n=108)$ & Term delivery $(n=795)$ & $p$-value & Odds ratio \\
\hline$\leq 10(91)$ & $17(18.7 \%)$ & $74(81.3 \%)$ & \multirow{2}{*}{0.033} & \multirow{2}{*}{1.82} \\
\hline$>10(812)$ & $91(11.2 \%)$ & $721(88.8 \%)$ & & \\
\hline$\leq 20(180)$ & $29(16.1 \%)$ & $151(83.9 \%)$ & \multirow{2}{*}{0.040} & \multirow{2}{*}{1.51} \\
\hline$>20(723)$ & $79(10.9 \%)$ & $622(89.1 \%)$ & & \\
\hline$\leq 30(268)$ & $38(14.2 \%)$ & $230(85.8 \%)$ & \multirow{2}{*}{0.112} & \multirow{2}{*}{1.33} \\
\hline$>30(635)$ & $70(11.0 \%)$ & $565(89.0 \%)$ & & \\
\hline$\leq 40(362)$ & $48(13.3 \%)$ & $314(86.7 \%)$ & \multirow{2}{*}{0.189} & \multirow{2}{*}{1.24} \\
\hline$>40(541)$ & $60(11.1 \%)$ & $481(88.9 \%)$ & & \\
\hline$\leq 50(449)$ & $59(13.1 \%)$ & $390(86.9 \%)$ & \multirow{2}{*}{0.162} & \multirow{2}{*}{1.20} \\
\hline$>50(454)$ & $49(10.8 \%)$ & $405(89.2 \%)$ & & \\
\hline
\end{tabular}

*Statistical test: Pearson Chi-square test; $p$-value significant if $<0.05$

Table 5: Correlation between the risk of preterm delivery with UEFW below $0.90,0.85,0.80,0.75 \mathrm{MoM} n=903$

\begin{tabular}{|c|c|c|c|c|}
\hline Deviations from the median in MoM & Preterm delivery $(n=108)$ & Term delivery $(n=795)$ & Significance ( $p$-value) & Odds ratio \\
\hline$\geq 0.90$ MoM (734) & $83(11.3 \%)$ & $651(88.7 \%)$ & \multirow{2}{*}{0.131} & \multirow{2}{*}{1.36} \\
\hline$<0.90$ MoM (169) & $25(14.8 \%)$ & $144(85.2 \%)$ & & \\
\hline$\geq 0.85 \operatorname{MoM}(830)$ & $93(11.2 \%)$ & $737(88.8 \%)$ & \multirow{2}{*}{0.024} & \multirow{2}{*}{2.08} \\
\hline$<0.85 \operatorname{MoM}(73)$ & $15(20.5 \%)$ & $58(79.5 \%)$ & & \\
\hline$\geq 0.80 \mathrm{MoM}(872)$ & $99(11.4 \%)$ & $773(88.6 \%)$ & \multirow{2}{*}{0.007} & \multirow{2}{*}{3.19} \\
\hline$<0.80$ MoM (31) & $9(29.0 \%)$ & $22(71.0 \%)$ & & \\
\hline$\geq 0.75 \mathrm{MoM}(891)$ & $102(11.4 \%)$ & $789(88.6 \%)$ & \multirow{2}{*}{0.001} & \multirow{2}{*}{7.77} \\
\hline$<0.75 \operatorname{MoM}(12)$ & $6(50.0 \%)$ & $6(50.0 \%)$ & & \\
\hline
\end{tabular}

*Statistical test: Pearson Chi-square test; $p$-value significant if $<0.05$

\section{DISCUSSION}

Discovering the predictors of preterm delivery helps in timely intervention with tocolytics to delay the progress of labor, administration of corticosteroids to bring about lung maturity and in utero transfer to a higher center for neonatal intensive care unit (NICU) care. Being product of the similar pathophysiology, fetal growth restriction can serve as a forerunner of spontaneous preterm labor.

In our study, 449 subjects had fetuses weighing $\leq 50$ th centile and 454 had those weighing above 50th centile. The distribution of subjects in different centile ranges below the 50th centile was more or less uniform avoiding the bias between the groups (Table 2). The demographic characteristics like maternal age, and parity influence the occurrence of preterm delivery. In our study they were matched in both the groups so also the age at which the UEFW was performed.
The mean UEFW at the time of estimation, of fetuses that had preterm delivery was significantly lesser (1455.57 $\pm 329.54 \mathrm{gm}$ ) when compared those that delivered at term $(1642.80 \pm 378.94 \mathrm{gm}) \mathrm{p}=0.028$ (Table 3 ) suggesting that growth restriction is a good predictor of preterm delivery. It is a known fact that growth restriction below the 10th centile is associated with an increased risk for preterm labor. This study was conducted to find out whether there is any significant risk when the fetus is between 10th and 50 th centile. Table 4 shows that the risk of preterm delivery is almost similar (16.1\%) when the cut-off is increased to 20th centile as when the cut-off is 10th centile $(18.7 \%)$. This finding was statistically significant also $(\mathrm{p}=0.040$, OR 1.51). However, the risk decreases as the fetal weight approaches 50th centile. Similarly, the fetuses with a UEFW below $0.85 \mathrm{MoM}$ had two fold and those below $0.80 \mathrm{MoM}$ had three fold increased risk to go into 
spontaneous preterm delivery $(\mathrm{p}=0.020$, OR 2.08 and 0.007 , OR 3.19 respectively) (Table 5). Both these findings reaffirm that not just the babies below 10th centile but those between 10 th and 20 th centilealso herald the risk of preterm delivery. This proves the hypothesis that suboptimal fetal weight and preterm delivery are linked and belong to the same spectrum with similar adaptive responses of the fetus to a hostile in utero environment, arising from any pathological process, such as intrauterine infection, placental insufficiency or an altered immunological response to the ongoing pregnancy.

Findings of our study were comparable to those conducted by Bukowski R et $\mathrm{al}^{2}$ and Lysikiewicz A et al. ${ }^{3}$ Both the studies had concluded that the growth impairment was more common in fetuses that delivered at preterm than at term and significantly more fetuses did not reach 5 th, 10th and 25th centile of their growth potential.

Another study involving 3653 uncomplicated pregnant women, showed that the odds ratio for preterm delivery increased even with slight deviation of UEFW below the median and with further deviation, the likelihood for preterm delivery increased drastically. ${ }^{1}$

A systematic review regarding the prediction of spontaneous preterm birth put forward the proposal that a more accurate prediction may be possible by combining several tests, including cervical length prediction and fetal fibronectin measurement in cervicovaginal fluid. ${ }^{4}$ But such tests deal with only one aspect of preterm labor, i.e. cervical changes and this may be too late to take appropriate preventive steps. Other aspect, namely fetoplacental developmental pathology, which results in fetal growth restriction may predict preterm labor earlier. Ultrasound estimation of fetal weight may hold good promise in predicting impending preterm labor and delivery well in time to intervene and prevent fetal morbidity.

\section{CONCLUSION}

In uncomplicated low-risk asymptomatic pregnancies between 28 and 34 weeks, an UEFW below 20th centile or a deviation below $0.80 \mathrm{MoM}$ increases the risk for spontaneous preterm delivery. Hence, it may be prudent to be vigilant and proactive when the fetal weight is between 10th and 50th centile especially when it is between 10th and 20th centile to avoid preterm delivery and subsequent fetal morbidity and mortality.

\section{REFERENCES}

1. Severi FM, Bocchi C, Imperatore A, Boni C, Ferrata C, Florio $P$, Reis FM, Petraglia F. Ultrasound estimated fetal weight slightly below the median is associated with increased risk of spontaneous preterm birth. Prenat Diagn 2012 Jun;32(6): 588-591.

2. Bukowski R, Gahn D, Denning J, Saade G. Impairment of growth in fetuses destined to deliver preterm. Am J Obstet Gynecol 2001 Aug;185(2):463-467.

3. Lysikiewicz A, BraceroLA, Tejani N. Sonographically estimated fetal weight percentile as a predictor of preterm delivery. J Matern Fetal Med 2001 Feb;10(1):44-47.

4. Honest H, Forbes CA, Duree KH, Norman G, Duffy SB, Tsourapas A, Roberts TE, Barton PM, Jonett SM, Hyde CJ, et al. Screening to prevent spontaneous preterm birth: systematic reviews of accuracy and effectiveness literature with economic modelling. Health Technol Assess 2009 Sep;13(43):1-627. 